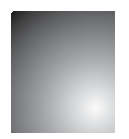

\title{
Design de Interação, Design Experiencial e DESIGN THINKING: A TRIANGULAÇÃO DA Interação Humano-Computador (IHC)
}

\author{
Interaction Design, Experiential Design and Thinking Design: \\ the triangulation of Human-Computer Interaction
}

\begin{abstract}
Cristiane Ellwanger
Doutoranda em Design - Área de Concentração Design e Tecnologia. Universidade Federal do Rio Grande do Sul. Porto Alegre, RS, Brasil.E-mail: cristianeellwanger@gmail.com
\end{abstract}

Rudimar Antunes da Rocha

Professor Associado IV do Departamento de Ciências da Administração. Universidade Federal de Santa Catarina. Florianópolis, SC, Brasil.E-mail: rrudimar@hotmail.com

Régio Pierre da Silva

Professor do Departamento de Design e Expressão Gráfica. Faculdade de Arquitetura da Universidade Federal do Rio Grande do Sul. Porto Alegre, RS, Brasil. E-mail: regio@ufrgs.br

\section{Resumo}

O artigo trata da Interação Humano-Computador (IHC) e suas interfaces na participação do usuário como pressuposto para a usabilidade de sistemas computacionais interativos e dinâmicos. A IHC advém do avanço das Tecnologias da Informação e Comunicação (TIC) e de marketing de relacionamento, por meio de como as pessoas se comportam frente ao Design de Interação (DI), Design Experiencial (DE) e Design Thinking (DT). Para ampliar as discussões, elaborou-se este trabalho, classificado como do tipo exploratório, analítico e descritivo pela literatura especializada dessas variáveis (HAIR JR.; ANDERSON; TATHAM, 2005). Da compreensão da IHC-TICs e da tríade do DI, DE e DT, reflete-se sobre o desenvolvimento de sistemas computacionais interativos. A pesquisa foi elaborada no terceiro trimestre de 2014. Concluiu-se que o DE é utilizado em contextos da IHC e TICs, englobando, DI ou DT da IHC, como objetos e sujeito que facilitam a experiência de sujeitos (designers e usuários) e objeto (produtos ou serviços) em que atuam.

Palauras-chave: Design de Interação. Design Experiencial. Design Thinking. Interação Humano-Computador.

\section{Abstract}

This article discusses the human-computer interaction (HCI), as interfaces that occur with user participation presupposes the usability of interactive computer systems. The $\mathrm{HCI}$ come from the advancement of information and communication technologies (ICTs) and relationship marketing, as well as the way people behave in front of Interaction Design (ID), the Experiential Design (ED) and the Design Thinking (DT). So to broaden the discussion on the issues, we prepared this essay classified as exploratory, descriptive and analytic selection of a type of literature (Hair, et al., 2005). Understanding of ICTs and HCI triangulation of ID, ED and DT was possible to reflect about the development of interactive computer systems. It can be concluded that the ED is used in several contexts $\mathrm{HCI}$ and ICTs, encompassing both the ID and the DT of HCI, objects, and subjected to facilitate the experience of individuals (designers and users) and object (or products services) in which they operate.

Keywords: Interaction Design. Experiential Design. Design Thinking. Human-Computer Interaction. 


\section{INTRODUÇÃo}

A Interação Humano-Computador (IHC) é mutante e se redimensiona com o surgimento de novas tecnologias da informação e comunicação (TICs), associada as técnicas de marketing de relacionamento emergentes nas últimas duas décadas. Como nestas áreas de conhecimento os avanços tecnológicos têm sido meteóricos, as definições da IHC precisam de revisões frequentes para se ajustar no tempo. Principalmente, porque os usuários de softwares interativos estão frente às várias interfaces de dispositivos computacionais, que trazem um conjunto prévio de conhecimentos e experiências de IHC, agregando-lhes um sistema de significação sociocultural (MIRAS, 2001). Esses avanços tecnológicos vêm modificando o mundo dos negócios e realinhando os seus usuários, portanto está circulado de vários desafios conceituais emergentes.

Por essas razões, julgou-se importante contribuir para a compreensão de definições que alicerçam a IHC pela ótica do Design de Interação (DI), do Design Experiencial (DE) e do Design Thinking (DT), tendo-se como pano de fundo o marketing de relacionamento online. Há centenas de estudos que abordam a IHC, mas não se encontrou nenhum deles que fizesse a correlação da supracitada triangulação, isto é, DI, DE e DT. A constatação desse hiato foi crucial para se escrever este ensaio, metodologicamente classificado como do tipo exploratório, analítico e descritivo, através da seleção e cruzamento da literatura especializada do tema (HAIR et al., 2005), bem como tratar do processo de aprendizagem das referidas variáveis, bem como se inserem na esfera dos sistemas computacionais interativos e de marketing de relacionamento. A seleção e o cruzamento da literatura deste artigo foram feitas no terceiro trimestre de 2014.

\section{Interação Humano-Computador}

A usabilidade é apontada na literatura especializada como base de Interação Humano-Computador e das abordagens sobre o Design de Interfaces (DI), o Design Experiencial (DE) e o Design Thinking (DT) são as formas com que as pessoas interagem com diferentes objetos que as cercam. A IHC é definida como atributo de qualidade e está relacionada à facilidade de uso de algo, da rapidez com que os clientes podem usar alguma coisa, da sua eficiência ao usá-la, bem como o quanto lembram os clientes do que obtiveram, do grau de propensão a erros ao usá-la e do quanto gostam de utilizá-la (NIELSEN; LORANGER, 2007), favorecendo o processo de relacionamento mercadológico das organizações com os usuários (BURNETT; MARIANTY, 1998; GORDON, 1998).

Pouco vale o desenvolvimento de produtos ou oferecimento de serviços, se eles não forem utilizados, pois "[...] se as pessoas não puderem ou não utilizarem um recurso, ele pode muito bem não existir" (NIELSEN; LORANGER, 2007). Os atributos de usabilidade (ROGERS; SHARP; PREECE, 2013; ROCHA; BARANAUSKAS, 2003) dizem respeito à facilidade de aprendizagem, à eficiência de uso, à facilidade de relembrar, à propensão a erros e à satisfação subjetiva, assim como na fidelização de pós-vendas com os usuários (GRÖNROOS, 2009). Na ótica de Lowdermilk (2013), a usabilidade corresponde a como os fatores humanos se relacionam com diferentes tipos de produtos e a como se relaciona ao design, à avaliação, ao desenvolvimento de sistemas computacionais interativos e aos principais fenômenos que os cercam (ROGERS et al., 2013).

Ampliando esse escopo, Carroll (2013) salienta que a IHC envolvem compreender, além das práticas humanas contemporâneas, as suas aspirações e forma com que determinadas atividades são elaboradas $e$ incorporadas na vida das pessoas, muitas vezes, limitadas em termos de infraestrutura e ferramentas atuais. Compreender as práticas $e$ as atividades envolvem requisitos, aliando possibilidades de se prever designs à concepção de novas tecnologias, ferramentas e ambientes. Trata-se da exploração de espaços de designs e desenvolvimento de novos sistemas e dispositivos da coevolução de atividades e artefatos: um ciclo denominado tarefa-artefato (Figura 1).

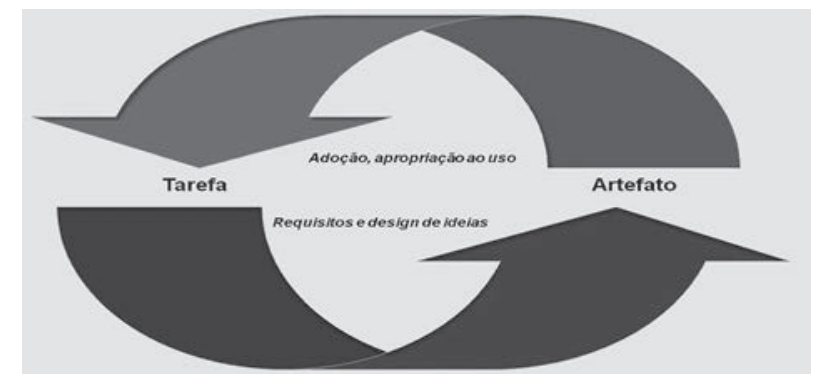

Figura 1: Ciclo Tarefa-artefato

Fonte: Adaptada de Carroll (2013) 
As atividades humanas $(\mathrm{AH})$ ou as tarefas a serem realizadas articulam necessidades, preferências e visões de design, enquanto os artefatos convergem em respostas, mas de forma mais significativa do que simplesmente responder. Ao aderir e se apropriar de um determinado artefato, são concebidos novos designs que proporcionam novas possibilidades de ação e de interação. As AHs articulam futuras necessidades humanas, preferências $e$ visões de design em um ciclo de melhoria contínua que determina a forma e maneira com que se projetam os diferentes dispositivos computacionais. Sobre essa questão, Krug (2008) salienta que as pessoas adoram fazer comentários sobre a aparência e, especialmente, sobre o uso de cores e ninguém deixa de usar uma aplicação computacional somente porque não tem ótima aparência, fortalecendo a ideia de marketing de relacionamento associada ao design do produto (CHURCHILL JR.; PETER, 2000; PAYNE et al., 1998).

Na visão de Benyon (2011, p. 48), “[...] design refere-se tanto ao processo criativo de especificar algo novo, quanto às representações produzidas durante este processo [...]", lembrando que para se projetar um site, o designer avaliará diversos designs, inserindo-se o layout das páginas, o esquema de cores, os gráficos e a sua estrutura, implicando em uma série de iterações e de explorações expressivas em termos de requisitos de sistemas e soluções de projeto.

Ao mencionar "sistemas computacionais interativos", na definição de IHC, a intenção é realmente excluir a grande variedade de objetos com os quais as pessoas interagem com frequência e que não apresentam vínculo com a computação, pois sistemas interativos são um termo utilizado para descrever tecnologias com as quais os designers de sistemas interativos trabalham, como dispositivos e sistemas de software, pois eles se relacionam com o processamento de informações que são disponibilizados para o mercado e precisam do alicerce dos profissionais de marketing para a sua popularização.

Já, para Benyon (2011), os sistemas interativos se direcionam para a exibição, a transmissão, o armazenamento ou a transformação de informações que são percebidas pelas pessoas, ou seja, sistemas que responde dinamicamente às ações das pessoas, o que é o caso de produtos como celulares, sites, controladores de jogos e, agregando-se às demais tecnologias que estão presentes na vida das pessoas, permitindo, de alguma forma, que se executem tais ações. Esse é o caso das tecnologias interativas não convencionais que podem ser aplicados em diferentes sentidos humanos, como: o tato, a audição, a visão. Esses sentidos humanos estão associados aos apelos utilizados no marketing de relacionamento, visando à fidelização dos clientes (GRÖNROOS, 2009; GORDON, 1998; McKENNA, 1992).

O grande desafio dos designers, desenvolvedores e analistas de sistemas interativos está na concepção de um design centrado no ser humano. Benyon (2011) vai ao encontro desse raciocínio e explica que uma abordagem centrada no humano tem por intuito colocar as pessoas em primeiro lugar, voltando-se ao projeto de sistemas interativos que favoreçam as pessoas e forneçam subsídios para que elas possam usufruir deles, para que seja possível volte a pensar o que as pessoas querem fazer em detrimento do que a tecnologia pode fazer com que se direcionem a projetar novas maneiras de conectar as pessoas, de envolvê-las no processo de design e de se projetar para a diversidade.

Lowdermilk (2013) referencia o design centrado no humano como Design Centrado no Usuário (DCU) e o conceitua como uma metodologia de design de software para desenvolvedores e designers, capazes de auxiliá-los na criação de aplicativos que atendam às necessidades de seus usuários, salientando que o DCU é proveniente da usabilidade e da interação humano-computador e que o posicionamento do usuário é o centro do processo e fator essencial para não ocorrer ambiguidades no processo de desenvolvimento de sistemas e se chegue ao eixo das necessidades.

Sob o aspecto da experiência e da usabilidade do usuário, a Figura 2 permite ver que a experiência do usuário é de fundamental importância, pois sintetiza a experiência que o usuário tem ao interagir com um software não envolvendo só a funcionalidade, mas o quanto é cativante e agradável às reações físicas e emocionais dos usuários.

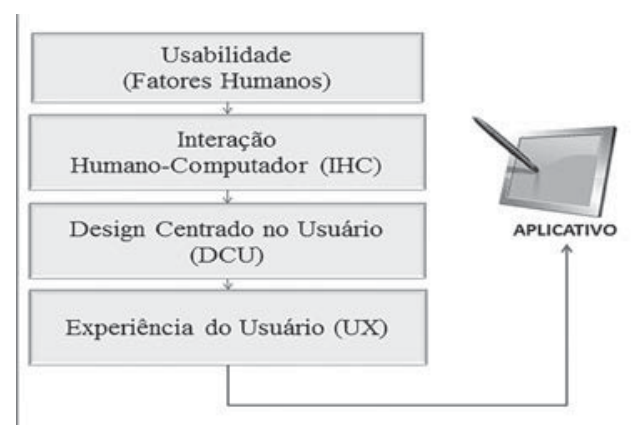

Figura 2: Relação entre usabilidade - IHC, DCU e UX Fonte: Adaptada de Lowdermilk (2013) 
Pode-se verificar que a relação está focada na funcionalidade do produto, portanto requer uma interpretação que envolva o DI.

\section{Design de Interação (DI)}

O Processo de Design de Interação (PDI) contempla o design de sistemas interativos e o planejamento das interações dos usuários sobre estes sistemas. O DI é apontado como um plano ou esquema preconcebido, com o intuito de ser executado, isto é, significa projetar designs que se voltem para o desenvolvimento desse esquema mental (ROGERS et al., 2013). A concepção de DI é complementada por Bevan (2009b), quando envolve situações de mudança, por meio da formulação e implantação de artefatos, isto é, na transformação e nos meios disponíveis para que o designer inicie mudanças em uma situação particular e analise o artefato projetado. Proveniente da IHC, o processo de DI traz a interface comunicacional de desenvolvedores e usuários para apregoar usabilidade como um dos pressupostos para que se tenham sistemas úteis, seguros e fáceis de manipular.

A usabilidade enfatiza a realização adequada de tarefas específicas em certos contextos de uso, mas com as novas tecnologias da Internet $e$ os players voltados as mídias portáteis, como os iPods, os usuários não estão necessariamente em busca da realização de alguma tarefa, mas buscam uma diversão atrelada a sua realização (ANTTONEN; JUMISKO-PYYKKÖ, 2008; HASSENZHL, 2013). A evolução da tecnologia muda a forma com a qual se interage com diferentes dispositivos computacionais e os objetivos que se busca a partir destas interações, estabelecendo concepções distintas de como as tarefas podem ser realizadas (Figura 3).
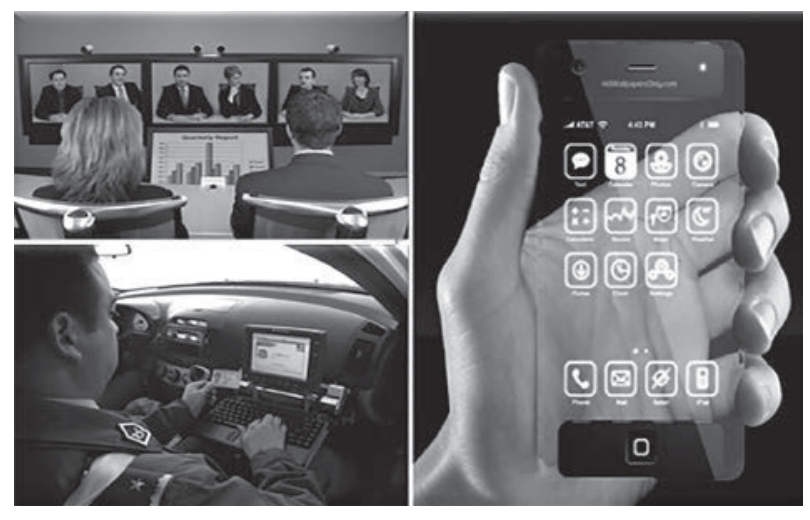

Figura 3: Formas distintas de interação com tecnologias Fonte: Adaptada de Carroll (2013)
O DI de diferentes dispositivos se altera e modifica os indivíduos à medida que interagem, sendo responsável em moldar as coisas digitais para uso das pessoas. A utilização de recursos digitais ligados aos ambientes de trabalho e a motivações instrumentais com o uso de programas para a realização de atividades de forma rápida, eficiente e correta se enriquece com crescer da tecnologia digital em ambientes móveis e na forma de produtos de consumo que trazem novas noções de uso, como entretenimento e prazer. A internet abriu caminhos de uso e de comunicação proeminente da tecnologia digital, retratado nas seguintes características do DI (LOWGREN, 2013).

A primeira característica do DI proporciona a exploração de futuros possíveis, pois permite dar enfoque ao que poderia ser a orientação, a análise e estudos críticos do que existe, acarretando consequências epistemológicas na forma com que pesquisas são conduzidas. Significa que muitas vezes faz sentido gastar um tempo maior nas fases iniciais de trabalhos divergentes, essencialmente, buscando ao seu entorno um espaço de designs possíveis antes de se direcionar a uma determinada direção. Explorar tendências em Design de Interação possibilita envolver ou convidar novos usuários para participarem da concepção de produtos computacionais ou não.

A segunda característica do DI visa a enquadrar o "problema" em paralelo com a criação de possíveis "soluções", pois é a partir das noções de situações de mudança e da exploração de possíveis demandas que se decide quando se deve criar algo, a situação em que esta novidade será competitiva. Imaginar o futuro implica não apenas pensar em diferentes soluções de design, mas em diferentes problemas, acarretando implicações ao design de interação contemporâneo, à medida que se volta a repensar as noções de especificação de forma exaustiva antes de construir suas abordagens.

A terceira característica do DI envolve o pensar, através de esboços e de outras representações tangíveis ao fazer mapas instantâneos de futuros possíveis. Os desenhos são micro experiências que respondem com insights dos pontos fortes, pontos fracos e das mudanças existentes numa iteração de pensamentos que envolvem tato, os demais sentidos e a mente. $\mathrm{O}$ ato de desenhar o futuro volta-se para a concepção do designer sobre o meio utilizado na representação externa, servindo para envolver o designer de interfaces 
em uma reflexão sobre os detalhes e as implicações das ideias não finalizadas.

A outra característica do DI aborda os aspectos instrumentais, técnicos, estéticos e éticos, haja vista que cada um dos possíveis futuros a serem explorados num processo de criação traz considerações e compensações em dimensões instrumentais, técnicas, estéticas e éticas, e não há qualquer maneira óbvia em que podem ser sequenciados. O uso de recursos tem um grande impacto sobre o $\mathrm{DI}$, principalmente no aumento da noção de experiência do usuário e na captura de todas as formas não instrumentais, estéticas, qualidades emocionais no uso de objetos e recursos digitais nas qualidades sociais por natureza.

\section{Design Experiencial (DE)}

Os dias atuais retratam crescimento exponencial de desenvolvimento e uso de diferentes tecnologias de informação e comunicação, direcionadas a muitos propósitos com características interligadas a mobilidade, capacidade de processamento e disponibilidade de informações sem restrições de tempo e espaço. Se num extremo pensar no desenvolvimento de tecnologias endereça a uma determinada situação, no outro extremo pensar na interação que esse processo vai gerar remete a outra situação, pois em todo momento se interage com diversos tipos de tecnologias.

Assim, a experiência advém da manipulação de recursos, sejam eles computacionais ou não, $e$ do uso que se faz destas tecnologias, originando-se do comportamento das pessoas em relação às outras pessoas e aos sistemas utilizados. Há como pressuposto a ação recíproca de indivíduos e objetos, diferenciando-se de interatividade por referenciar a capacidade ou o potencial que um sistema apresenta de interação como pré-requisito para ela (FIALHO, 2001), ou porque o projeto de produtos interativos usáveis requer a observância de seu contexto de uso, quem e onde eles serão utilizados e da compreensão do tipo de atividade que as pessoas realizam ao interagirem com determinado produto ou serviço (ROGERS et al., 2013).

Na concepção de Buccini e Padovani (2005), a experiência é vista como um fenômeno individual que ocorre na mente de cada indivíduo e resulta de um complexo processamento de estímulos internos e externos, dependente de interpretações subjetivas inerentes a cada pessoa, até mesmo porque, nas palavras de Schmitt (2000), as experiências podem ser vistas como acontecimentos individuais decorrentes de algum estímulo de uma observação direta ou da participação nos acontecimentos reais, imaginários ou virtuais. Sobre isso, Garrett (2011) salienta que a experiência do usuário é definida, por meio do comportamento do produto (objeto) e da forma com que ele é utilizado, isto é, advém do contato (interação) do usuário com o produto (objeto), indo além das funcionalidades e recursos inerentes.

Percebe-se que projetar a experiência não é uma tarefa fácil, pois elas se estabelecem nos indivíduos de forma única e variam em situações distintas. A perspectiva experiencial traz a ideia de que as experiências dos usuários podem ser influenciadas por atributos intangíveis do produto, como o design (SOLOMON, 2007), dando-se pelos sentidos, sentimentos, pensamentos, ações e interações dos elementos na interação do usuário versus o produto (SCHMITT, 2000), que culmina com o fortalecimento da aplicação de técnicas de marketing de relacionamento (GORDON, 1998).

Apesar da subjetividade desses aspectos, Suri (2003) acredita que designers da computação projetam mais que objetos estáticos, pois há interações e dinâmicas integradas dos objetos, espaços e serviços. O projetista de interface precisa compreender as experiências dos usuários e formas de se projetar as dimensões dessa experiência, utilizando-se ferramentas de modelagem, usadas para explorar as distintas ideias de design, pois os resultados das interações não são capazes de serem supridos somente pelo objeto (PIAGET, 1977; PIAGET, 1995), ou que a experiência do usuário pode ser vista como o conjunto de todos os processos, sejam eles físicos, cognitivos ou emocionais, provenientes da interação do usuário com um determinado produto/serviço, em momentos que vão desde a expectativa da interação à interação propriamente dita e à reflexão após a interação, considerando um determinado contexto de uso, seja ele físico, social ou tecnológico (CYBIS; PEREIRA, 2010).

Assim, o DE pode servir de subsídio a estes profissionais que estabelece a prática do design, o qual busca atender às necessidades imediatas e objetivas 
do usuário, entender e preencher as motivações $e$ aspirações humanas em relação ao produto, estando relacionado às experiências da vida (FORLIZZI et al., 2003; FORLIZZI et al., 2000). Os fatores ligados à experiência são subjetivos e dependem de aspectos dinâmicos difíceis de serem previstos e mensurados, pois as experiências anteriores, gostos $e$ ideias que mudam com o tempo e situações da vida de cada indivíduo (JÄÄSKÖ et al., 2003). Além disso, o DE apresenta-se como um novo paradigma, estabelecendo a necessidade de compreender o comportamento humano, identificando variáveis relacionadas à experiência estética, de significado e o emocional dos usuários, visando à abordagem holística dos aspectos racionalistas, ligados à funcionalidade $e$ usabilidade, e aspectos experienciais, relacionados à emoção e ao prazer (HOWARD; MELLES, 2011; CYBIS; PEREIRA, 2010).

O DE busca entender e preencher as motivações humanas e emocionais dos usuários, além das preocupações racionalistas exploradas pelo design tradicional (BUCCINI; PADOVANI, 2005), para compreender o conjunto de ideias, sensações e valores dos usuários resultantes da interação com um produto, estabelecendo como resultado os objetivos do usuário, variáveis culturais e desenho da interface que específica, o fenômeno resultante $e$ fatores que acabam influenciando na interação (HOWARD; MELLES, 2011; YUSEF et al., 2005).

Para Garrett (2011), o DE estabelece interfaces digitais em cinco elementos. A estratégia corresponde a uma determinada aplicação $e$ incorpora, não apenas o que as pessoas que gerenciam a aplicação querem, mas o que os usuários desejam. O escopo representa a forma em que as características e as funções se encaixam, definindo os requisitos em relação ao conteúdo e às especificações funcionais que devem ser contempladas na aplicação. Já a estrutura abrange a arquitetura das informações e o design de interação. Por sua vez, o esqueleto (Skeleton) representa a estrutura abstrata da aplicação dos elementos de interface na página, de checkout, botões, colocação do controle, fotos e blocos de texto. Enquanto a superfície envolve o design visual da aplicação, a sua apresentação é composta por imagens e textos (Figura 4).

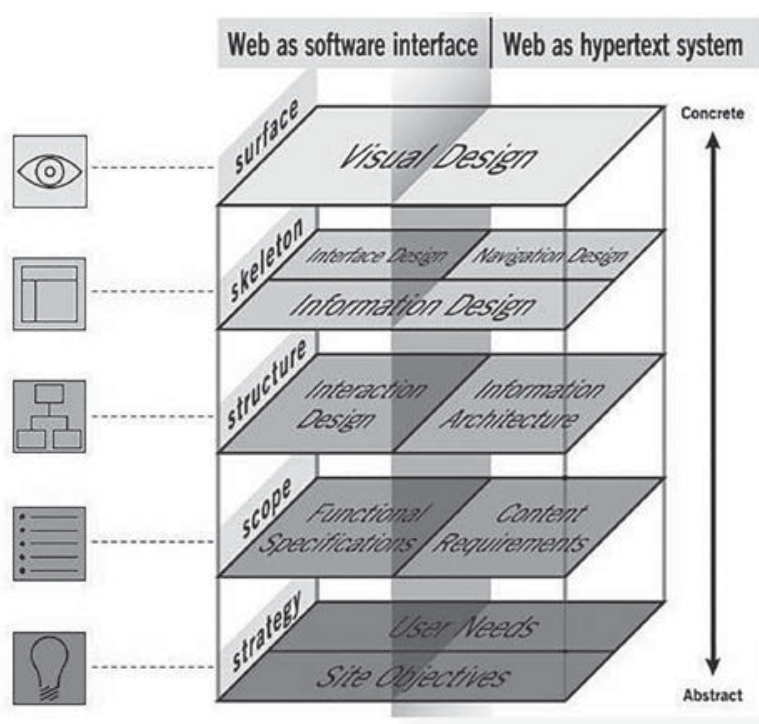

Figura 4: Elementos do Design Experiencial

Fonte: Garrett (2011, p. 29)

O DE abrange as experiências sobre diferentes enfoques, categorizando-as em experiências relacionadas aos sentidos, aos sentimentos, sociais e cognitivas que vêm da interação dos usuários com sistemas computacionais. Para Buccini (2008) e Buccini e Padovani (2005), as experiências relacionadas aos sentidos ocorrem de forma imediatas e instintivas, sendo diretamente ligadas aos órgãos sensoriais e associadas a estímulos como: aparência, audição, toque ou sensações que se tem do produto, enquanto as experiências relacionadas aos sentimentos unem-se às emoções dos usuários ao utilizar um produto.

No DE a comunicação é de suma importância, em função da complexidade implícita nos contextos em que ocorrem as interações, as quais se encontram envoltas em quantidades expressivas e múltiplas de dispositivos, cercadas por uma realidade de ubiquidade computacional (BEVAN, 2009b), transmitindo significados às interfaces da aparência e funcionalidades (ANTTONEN; JUMISKO-PYYKKÖ, 2008).

\section{Design Thinking (DT)}

Os novos campos do design têm evoluído nas últimas décadas, dando enfoque ao design de objetos e de sistemas, bem como no relacionamento entre os designs concebidos e seus usuários. Isto representa a mudança do foco de produção, funcionalidade e 
importância semiótica de se projetar coisas no século XXI. Há necessidade da visão ampliada sobre experiência do usuário no contexto de desenvolvimento de tecnologias digitais. Uma das maiores qualidades do DT é a sensibilidade estética das estruturas de texto e da organização de argumentos (CARROLL, 2013; VIANA et al., 2012).

Na concepção de Viana et al. (2012), o DT inova ao trazer novos significados aos produtos, serviços ou relacionamentos, considerando que as coisas devam ter forma para serem vistas, mas precisam fazer sentido para que possam ser compreendidas e utilizadas. A maneira com que o DI e o DT são similares na resolução de problemas, por um lado o DI se concentrar no entendimento de experiências humanas holísticas a partir do uso de sistemas e todas as suas formas de interação, sejam elas físicas ou tecnológicas e, por outro lado, o DT oferece abordagens para facilitar a experiência dos usuários em direção a resultados holísticos (HOWARD; MELLES, 2011).

Ao desafiar os padrões de pensamento, comportamento e sentimento, os DT dão soluções que geram novos significados e que estimulam os diversos aspectos, sejam cognitivos, emocionais e sensoriais envolvidos na experiência humana, refletindo-se na maneira do designer pensar, usando um tipo de raciocínio pouco convencional ou pensamento abdutivo. Ao pensar de maneira abdutiva, a solução não é derivada do problema, porém se encaixa nele (VIANA et al., 2012). Essa forma de pensamento estabelece nos projetistas de interfaces a estruturação de esquemas mentais para sua concepção, reunindo o que é possível de se generalizar em uma determinada ação. Advertem ainda que o estabelecimento do processo criativo no DT fundamenta-se em três fases: a imersão, a ideação e a prototipação (VIANA et al., 2012).

A fase de Imersão abrange a análise e síntese de atividades, dividida em duas etapas: a preliminar que tem como objetivo o reenquadramento $e$ o entendimento inicial do problema e, a em profundidade que se destina à identificação de necessidades e oportunidades que nortearão a geração de soluções na fase posterior (ideação) e tem por intuito a análise e a síntese de dados. Após as etapas de levantamento de dados da fase de Imersão, direciona-se à análise e à síntese das informações coletadas através de insights que são organizados de maneira a se obter padrões e a criar desafios que auxiliem na compreensão do problema. A imersão envolve uma compreensão abrangente do problema a ser resolvido e parte de pontos superficiais a pontos expressivos em termos de profundidade (Figura 5).

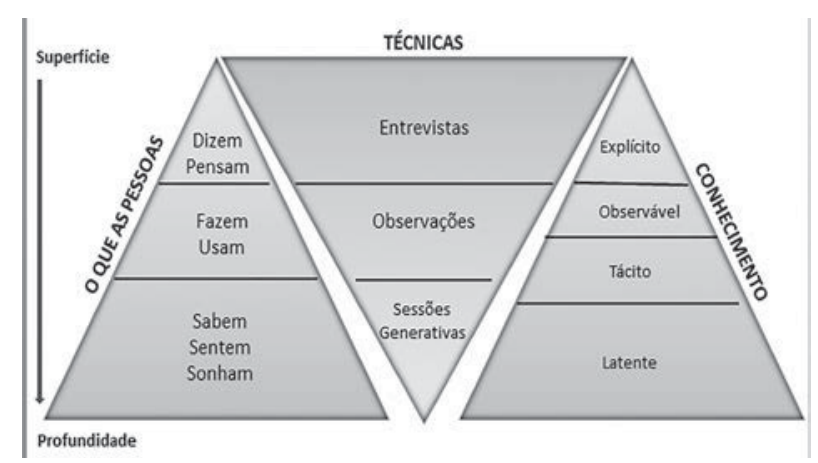

Figura 5: Pontos a serem observados na fase de Imersão do Design Thinking

Fonte: Adaptada de Viana et al. (2012)

O entendimento das pessoas do escopo do problema envolve compreendê-las, analisar as técnicas que subsidiam essa compreensão para se obter o conhecimento específico que viabiliza a sua aplicação em contextos distintos e servem de base para as fases subsequentes, isto é, a ideação e a prototipação. A fase de Ideação tem como intuito gerar ideias inovadoras para o tema do projeto e, nela, são utilizadas ferramentas de síntese criadas na fase de análise para estimular a criatividade e gerar soluções que estejam de acordo com o contexto a ser trabalhado.

\section{Correlações das Abordagens}

Várias correlações podem ser observadas nas conceituações descritas nos tópicos anteriores. Alguns autores abordam tais abordagens sobre diferentes enfoques. Alguns de forma mais sutil e outros de forma mais discrepante. Para alguns autores, o DE integra-se ao $\mathrm{DI}$ e pode ser relacionada a um dos atributos de usabilidade de Nielsen, Loranger (2007), denominado "satisfação subjetiva", haja vista que alguns estudiosos explanam sobre este atributo e retratam questóes voltadas à experiência do usuário (ROCHA; BARANAUSKAS, 2003), havendo semelhanças entre os referidos conceitos (BEVAN, 2009a; BEVAN, 2009b).

Na ISO 9241-210 (ISO, 2008b), a experiência do usuário é definida como as percepções e as respostas 
de uma pessoa, resultantes do uso e/ou da antecipação de um produto, sistema ou serviço, enquanto a usabilidade é referenciada como a medida sob a qual um sistema, produto ou serviço é utilizado por usuários para alcançar objetivos específicos com efetividade, eficiência e satisfação em um contexto de uso específico, não existindo preocupação com o decorrer do tempo. Perceba que a definição de usabilidade, retratada na ISO 9241-171 (ISO, 2008a), não traz nada sobre a capacidade de aprendizado ou a definição de experiência do usuário (ISO, 2008b), nem aborda a forma como a experiência do usuário evolui da expectativa para uma interação real ou para uma experiência total, incluindo uma reflexão da experiência que se tem (ROTO, 2008; ROTO et al., 2009).

Já as teorias que giram em torno da IHC estão firmadas na interação que se tem com os mais variados tipos de aplicações e de como as interações se enriqueceram ao longo do tempo. As teorias da percepção explicam como os objetos são reconhecidos em displays gráficos, enquanto as teorias de modelos mentais se empenham em explicar regras de conceitos, bem como as metáforas direcionadas a desktops, enquanto na formação de interações, as teorias sobre usuários se detêm em explicar como e por que os usuários aprendem e dão sentido a suas interações (CYBIS et al., 2010; LOWDERMILK, 2013; ROGERS et al., 2013).

As correntes teóricas podem ser identificadas e agrupadas em três enfoques: as teorias da IHC centradas no processamento de informações; as teorias que visualizam as iniciativas de interação para o design de agentes; $e$, as teorias que veem a interação como incorporada ao social $e$ o material em contextos específicos. Até certo ponto, essa sequência de teorias pode ser entendida como uma convergência de oportunidades científicas e a sua necessidade de aplicação, codificação e utilização de modelos deixam claro que as visões distintas das pessoas e suas diferentes interações com os objetos podem ser articuladas, trazendo contribuições aos aportes teóricos mais ricos para sua análise e design (BEVAN, 2009b). Até mesmo porque, a IHC agrega, em si, uma quantidade expressiva de áreas do conhecimento e de habilidades que se fazem necessárias nos indivíduos, não somente para a concepção de sistemas interativos, mas para a compreensão dos fenômenos que os cercam, pois o leque de conhecimentos e habilidades que envolvem o DE e o DI é vasto, tornando-se complexo quando não se conhecem as fronteiras que delimitam tais abordagens.

Acerca dessas inquietudes, Carroll (2013) defende que há uma tendência na IHC, na engenharia de usabilidade e nas teorias que abordam fatores humanos, em se concentrar nos aspectos instrumentais $e$ técnicos. Ele assevera que o design de interação deve ser visto como uma atividade em que as qualidades estéticas e éticas não podem ser ignoradas ou deixadas de lado. Se algo parece ser bom e agradável de utilizar e se isso torna as pessoas confortáveis em termos de responsabilidade social e padrões morais, isso tem um impacto real não só na experiência geral do usuário, mas em resultados instrumentais e mensuráveis que delineiam o DI, DE e DT, embora o DT ainda não tenha sido abordado na literatura relacionada à IHC, é evidente que ele se insere nela, à medida que o designer tem um papel fundamental na concepção de interfaces de usuário, conforme representa a Figura 6.

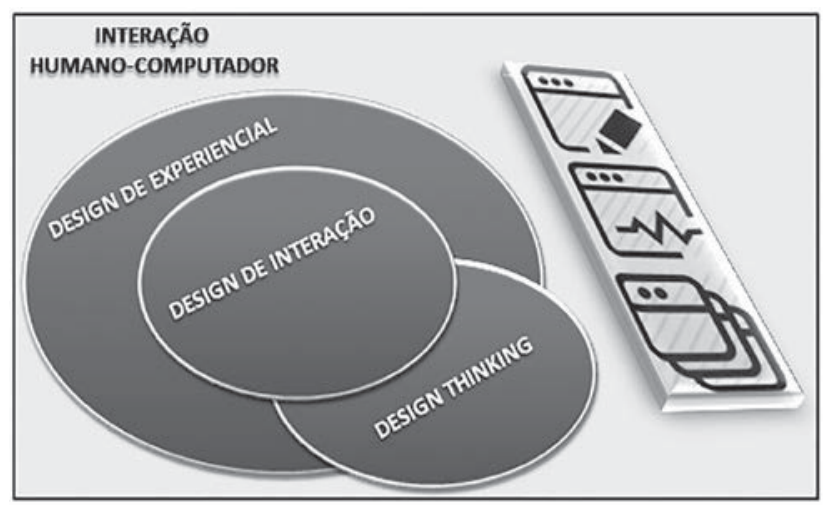

Figura 6: Agregação entre as conceitualizações Fonte: Carroll (2013, p. 57)

Sobre o ponto interpretativo de Lowdermilk (2013) não há como diferenciar o design centrado no usuário do DI, pois ambas têm os mesmos pressupostos e caracteríriscas. O que se amplia é a forma de se representar o DI, pois ele se encontra em um escopo abrangente referenciado na literatura (BUCCINI, 2008; BUCCINI; PADOVANI, 2005) ou como DE voltando as experiências que são significativas e gratificantes aos olhos do usuário (HASSENZHL, 2013), mas pode se fortalecer quando a fidelização do usuário se cristaliza representado por ações de marketing de relacionamento em vários aspectos de acessibilidade para o usuário, conforme sinalizam (GRÖNROOS, 2009; PAYNE, et al., 1998; McKENNA, 1992). 


\section{Conclusões}

A partir das abordagens descritas das análises de vários estudiosos, das correlações estabelecidas e das inferências que se pode fazer, verificou-se que o DE pode ser utilizado em uma infinidade de contextos específicos e engloba tanto o DI quanto o DT, apresentando um escopo abrangente de todo processo interacional estabelecido entre objetos e sujeito por permitir e facilitar a concepção de produtos/serviços que se voltam para a experiência do cliente, considerando os sujeitos (designers e usuários) e o objeto (produtos ou serviços) sobre o qual os sujeitos atuam.

Na concepção e no uso de sistemas digitais interativos, o DE fundamenta-se nas fronteiras entre a $\mathrm{IHC}$ e a de DI, as quais salientam que o objeto e a sua interação são componentes indispensáveis e necessários para que a experiência do cliente ocorra de forma satisfatória por ser esse o foco central. Seu escopo é tão amplo que agrega em si características e experiências dos próprios projetistas (DT) à experiência do cliente, a partir da concepção de esquemas mentais que dão suportes às práticas de prototipação, propiciando a melhoria contínua das interfaces por eles projetadas, seguindo os pressupostos de Piaget (1995).

Já, o DE tem como objetivo o projetar para a experiência do usuário, na tríade designer-sistema-usuário (IHC), o designer agrega nos sistemas e nas interfaces que projeta partes de si, a partir de assimilações do objeto (sistema/protótipo), provenientes de sistemas preconcebidos ou a partir de suas experiências em sistemas similares existentes, bem como de suas vivências e concepções que tem do mundo que os cerca. Ele é capaz de realizar uma série de ações sucessivas e coordenadas, de construir com ou sem narrativas o processo de projetar para a experiência e de fazer comparações que o levam à reflexão ou ao pensamento reflexivo de sua ação, fazendo com que ele possa expressar todo o conhecimento adquirido, construindo-o e reconstruindo-o sob a forma de representações orais, pictóricas ou escritas.

Logo, sempre que a ação de projetar para a experiência, no caso do DE for proveniente de uma necessidade do designer de interfaces ela irá transformar em novo sujeito. Sujeito este que supera a si mesmo não somente a partir da manipulação do objeto, mas a partir das interações realizadas com o usuário e no meio em que ambos se encontram inseridos, chamado de contexto de uso. Esses são os motivos pelos quais se faz necessário dedicar uma atenção especial ao DE, não somente sobre a perspectiva do usuário (DI), mas sob a perspectiva do próprio projetista de sistemas interativos (DT), pois como se poderá projetar para a experiência se eles não compreendem como suas próprias experiências se estabelecem nas interfaces que projetam.

Sob o aspecto do marketing de relacionamento, a triangulação sugerida do IHC fortalece a ideia de que o usuário sente a necessidade de ver a sua satisfação, pela contratação do serviço ou aquisição de produto, com o elo do reconhecimento e credibilidade do pós-vendas. Avanços interpretativos são necessários para uma configuração definitiva, por isso a reflexão sobre o que se expôs está aberta para questionamentos científicos a esta configuração.

\section{REFERÊNCIAS}

ANTTONEN, J.; JUMISKO-PYYKKÖ, S. Understanding the Meaning of Experiences with Technology. In: WORKSHOP. Research Goals and Strategies for

Studying User Experience and Emotion, 2008.

Disponível em: < http://www.cs.tut.fi/ihte/research/ publications.shtml>. Acesso: $1^{\circ}$ mar. 2013.

BARBOSA, S. D.; SILVA, B. S. Interação Humano-

Computador. Rio de Janeiro: Elsevier, 2010.

BECKER, F. Educação e construção do conhecimento. 2. ed. Porto Alegre: Penso, 2012.

BENYON, D. Interação Humano-Computador. 2. ed, São Paulo: Pearson Prentice Hall, 2011.

BEVAN, N. Extending quality in use to provide a framework for usability measurement. Proceedings of HCI International. San Diego, California, USA, 2009a.

BEVAN, N. What is the difference between the purpose of usability and user experience evaluation methods? In: WORKSHOP. On User Experience Evaluation Methods in Product Development during Interact 09 Conference. 2009b. Disponível em: <http://nigelbevan. com/papers/What_is_the_difference_between_usability_ and_user_experience_evaluation_methods.pdf $>$. Acesso: $1^{\circ}$ jul. 2013. 
BUCCINI, M. B. P. R.; PADOVANI, S. Design experiencial na Internet. In: II CONGRESSO INTERNACIONAL DE DESIGN DA INFORMAÇÃO. 2005. São Paulo: Anais..., São Paulo, 2005.

\section{BUCCINI, M. B. P. R. Introdução ao Design}

Experiencial. 1. ed. Recife: Edição do Autor, 2008.

BURNETT, J.; MARIANTY, S. Introdution to marketing communications. Europe: Prentice Hall, 1998. 659 p.

CARROLL, J. Human Computer Interaction - brief intro. In: SOEGAARD, Mads; DAM, Rikke Friis (Ed.). The

Encyclopedia of Human-Computer Interaction. 2nd ed. Aarhus, Denmark: the Interaction Design Foundation. 2013. Disponível em: <https://www.interaction-design.org/ encyclopedia/human_computer_interaction_hci.html>. Acesso em: $1^{\circ}$ ago. 2013.

CHURCHILL JR., G. A.; PETER, J. P. Marketing: criando valor para os clientes. São Paulo: Saraiva, 2000.

CYBIS, A. T.; PEREIRA, B. S. G. (Org.). Design de hipermídia: processos e conexões. 1. ed. Florianópolis: UFSC/CCE, 2010.

DEIVIS, M. Theoretical Foundations for Experiential Systems Design ETP'03. November 7, 2003. Berkeley, California, USA: Copyright 2003. ACM.

FIALHO, F. Ciências da cognição. Florianópolis: Insular, 2001.

FORLIZZI, J.; DISALVO, C., HANINGTIN, B. Emotion, experience and the design of new products. The Design Journal, London, UK, v. 6, n. 2, p. 29-38, 2003.

FORLIZZI, J.; FORD, S.; HANINGTIN, B. The building blocks of experience: An early framework for interaction designers. In: CONFERENCE ON DESIGNING INTERACTIVE SYSTEMS: PROCESSES, PRACTICES, METHODS, AND TECHNIQUES, 3, New York City.

Anais... New York, 2000. p. 419-423.

\section{GARRETT, J. J. The Elements of User Experience:} user-centered design for the web and beyond. 2. ed. Berkeley, CA: Tracey Croom, 2011.

GORDON, I. Marketing de relacionamento: estratégias, técnicas e tecnologias para conquistar clientes e mantê-los para sempre. São Paulo: Futura, 1998.
GRÖNROOS, C. Marketing: gerenciamento e serviços. Rio de Janeiro: Campus, 2009.

HAIR JR., J. F.; ANDERSON, R. E.; TATHAM, R. L.; Black, W. C. Análise multivariada de dados. Porto Alegre : Bookman, 2005.

HASSENZHL, M. User Experience and Experience Design. In: SOEGAARD, Mads; DAM, Rikke Friis (Ed.). The Encyclopedia of Human-Computer Interaction, 2nd ed. Aarhus, Denmark: The Interaction Design Foundation. 2013. Disponível: <http://www. interaction-design.org/encyclopedia/user_experience_and_ experience_design.html>. Acesso em: $1^{\circ}$ set. 2014.

\section{HOWARD, Z.; MELLES, G. Beyond designing:} roles of the designer in complex design projects. In: PROCEEDINGS OF THE 23RD AUSTRALIAN COMPUTER-HUMAN INTERACTION CONFERENCE. ACM New York, NY, USA, 2011. Anais... New York, 2011.

ISO - INTERNATIONAL STANDARDS ORGANIZATION.

ISO 9241-171: ergonomics of human-system interaction. Part 171: Guidance on software accessibility. Geneva: International Standards Organization, 2008a.

ISO - INTERNATIONAL STANDARDS ORGANIZATION. ISO DIS 9241-210: Ergonomics of human- system interaction. Part 210: Human-centred design process for interactive systems (formerly known as 13407). Geneva: International Standards Organization, 2008b.

JÄÄSKÖ, V.; MATTELMÄKI, T.; YLIRISKU, S. The scene of experiences. The good, the bad and the irrelevant conference. Proceedings... Helsinki: University of Art and Design Helsinki, september, 2003. p. 32-58.

KRUG, S. Não me faça pensar. 2. ed. Rio de Janeiro: Alta books, 2008.

\section{LOWDERMILK, T. Design Centrado no Usuário: um} guia para o desenvolvimento de aplicativos amigáveis. São Paulo: Novatec, 2013.

LOWGREN, J. Interaction Design - brief intro. In: SOEGAARD, M.; DAM, R. F. (Ed.). Encyclopedia of Human-Computer Interaction. 2nd ed. Aarhus, Denmark: The Interaction Design Foundation, 2013. Disponível em: $<$ https://www.interactiondesign.org/encyclopedia/interaction design.html >. Acesso em: 1 jul. 2013. 
McKENNA, R. Marketing de relacionamento:

estratégias bem-sucedidas para a era do cliente. Rio de Janeiro: Campus, 1992.

MIRAS, M. Um ponto de partida para a aprendizagem de novos conteúdos: os conhecimentos prévios. In: COLL,

César et al. (Org.). O construtivismo na sala de aula. 6. ed. São Paulo: Ática, 2001. p. 57-77.

\section{NIELSEN, J.; LORANGER, H. Usabilidade na Web} projetando sites com qualidade. Rio de Janeiro: Elsevier, 2007.

PAYNE, A.; MARTIN, C.; CLARK, M.; PECK, H.

Relationship Marketing for competitive advantage.

Oxford: Butterworth \& Heinemann, 1998.

PEIRCE, C. S. The collected papers. (Org.).

HARTSHORNE, Charles et al. Cambridge, MA: Harvard University Press, v. 7-8, 1931-1958.

PIAGET, J. A tomada de consciência. São Paulo: Melhoramentos, 1977.

. Abstração Reflexionante: relações lógicoaritméticas e ordem das relações espaciais. Porto Alegre: Artmed, 1995.

O nascimento da inteligência na criança. Rio de janeiro: Zahar, 1978.

PINHEIRO, M. Do design de interface ao design da experiência. Revista Design em Foco, Salvador: EDUNEB, v. IV, n. 2, jul.-dez. p. 9-23, 2007.

ROCHA, H. V.; BARANAUSKAS, M. C. C. Design

e avaliação de interfaces humano-computador. Campinas, SP: UNICAMP-IC-NIED, 2003. p. 244.

ROGERS, Y.; SHARP, H.; PREECE, J. Design de

Interação: além da interação humano-computador. 3. ed. Porto Alegre: Bookman, 2013.

ROTO V.; OBRIST, M.; VÄÄNÄNEN-VAINIO-MATTILA, K. In: WORKSHOP. User Experience Evaluation Methods in Academic and Industrial Contexts. Proceedings of UXEM, 2009.

ROTO, V. User Experience Research in the Design and Development Phase. In: WORKSHOP. Keynote at the User Experience \& User Generated Content workshop, Salzburg, Austria, 2008. Disponível: <http:// www.icts.sbg.ac.at/media/pdf/pdf1684.pdf> . Acesso em: $1^{\circ}$ out. 2013.

SCHMITT, B. Marketing experimental. São Paulo: Nobel, 2000.

SOLOMON, M. R. O comportamento do consumidor: comprando, possuindo e sendo. 5. ed. Porto Alegre:

Bookman, 2002.

SURI, J. F. The Experience of evolution: developments in design practice. The Design Journal, [S.I.], v. 6, n. 2, p. 39-48, Jully, 2003.

VIANA, M. et al. Design thinking: inovação em negócios. Rio de Janeiro: MJV Press, 2012. 162 p.

YUSEF, H. M.; MARTÍN FERNÁNDEZ, F. J. La

Experiencia del Usuario. No Solo Usabilidad, [S.l.], n. 4, 2005. Disponível em: < http://www.nosolousabilidad. com/>. Acesso em: $1^{\circ}$ nov. 2014. 